\title{
A AUTORA IMPROVÁVEL: ESCRITA, FOME E POLÍTICA NA PERSPECTIVA DE CAROLINA DE JESUS
}

\section{THE UNLIKELY AUTHOR: WRITING, HUNGER AND POLITICS FROM THE PERSPECTIVE OF CAROLINA DE JESUS}

\author{
Bruna Alves Lopes ${ }^{1}$ \\ Elaine Cristina Quadros Dubiel ${ }^{2}$
}

\begin{abstract}
Resumo: O presente trabalho tem como proposta analisar a obra Quarto de Despejo, de autoria de Carolina de Jesus, enfatizando a crítica na articulação existente entre escrita, fome e política tal qual estabelecida pela escritora. Neste artigo entendemos o livro em questão como um artefato que nos permite lançarmos novos olhares para o período histórico denominado como Anos Dourados, pluralizando as vozes do passado e, consequentemente, ampliando nossa percepção acerca desse período da história do Brasil. Concluímos que a escrita possibilitou a construção de uma outra imagem de si, além de ter se tornado um instrumento de prazer e resistência num cotidiano marcado pela extrema pobreza, além de oferecer recursos para que a mesma pudesse elaborar uma explicação para o que vivenciava.
\end{abstract}

Palavras-chave: Carolina de Jesus; Escrita; Fome; Política.

Abstract: The present work aims to analyze the work Quarto de Despejo, written by Carolina de Jesus, emphasizing the criticism in the existing articulation between writing, hunger and politics as established by the writer. In this article we understand the book in question as an artifact that allows us to take a new look at the historical period called Golden Years, pluralizing the voices of the past and, consequently, expanding our perception about this period in the history of Brazil. We conclude that writing enabled the construction of another image of the self, in addition to having become an instrument of pleasure and resistance in a daily life marked by extreme poverty, in addition to offering resources so that it could elaborate an explanation for what it experienced.

Key words: Carolina de Jesus; Writing; Hunger; Politics.

1 Professora Colaboradora do departamento de história na Universidade Estadual de Ponta Grossa. E-mail: bruna.hist. uepg@gmail.com.

2 Graduada em Licenciatura em História pela Universidade Estadual de Ponta Grossa e acadêmica de Pedagogia na Universidade Cruzeiro do Sul Educacional.E-mail: elain.dubiell@hotmail.com. 


\section{INTRODUÇÃO}

No dia 19 de agosto de 1960 a Livraria Francisco Alves recebeu Carolina de Jesus para que esta pudesse divulgar e autografar o seu primeiro livro: Quarto de Despejo. A obra inicialmente negada por algumas editoras, mas publicada devido ao apoio do jornalista Audálio Dantas (DA COSTA, 2007) - trouxe ao público o testemunho acerca do cotidiano dos moradores da extinta favela do Canindé, em São Paulo.

O livro despertou o interesse de leitores de diferentes nacionalidades sendo publicado

[...] em 13 línguas em mais de 40 países, incluindo a então União Soviética e o Japão. Sua projeção foi vertiginosa, e jamais outro livro publicado no Brasil com testemunho de mulheres pobres alcançou níveis equiparáveis ao de Carolina. (MEIHY, LEVINE, 1994 apud DOS SANTOS, 1996, p.14).

De acordo com Da Costa (2007, p. 18), Carolina “[...] freqüentou o Colégio Allan Kardec, de Sacramento, instituição financiada por Maria Leite Monteiro de Barros, para quem a mãe de Carolina lavava roupas e que se dispôs a contribuir para a educação da menina”. Obteve apenas dois anos de educação escolar, embora a mãe sonhasse com a filha se tornando professora. Sobre o assunto, Carolina escreveu em seu diário: "[...] foi as contingências da vida que lhe impossibilitou concretizar o seu sonho". (DE JESUS, 2014 p.48-49).

Se as eventualidades da vida não permitiram que Carolina Maria de Jesus obtivesse o título de professora, estas não conseguiram silenciar sua voz; que foi ouvida, estudada e analisada em alguns países.

Apesar do sucesso, Da Costa (2007) nos informa que Carolina passou por um processo de marginalização por parte de diferentes grupos: a chamada classe média não aceitava o sucesso de seu trabalho, a esquerda da época considerava seu discurso contraditório e sem consciência de classe, o movimento feminista (centrado nas demandas das mulheres brancas e de classe média) não incorporou as questões colocadas por uma mulher pobre, negra e única responsável na criação de três crianças e, por fim, a intelectualidade da época, marcada muitas vezes pelo racismo e pelo preconceito da sociedade daquele período (ALMEIDA, 2020), não valorizava seus escritos e questionava o status de escritora a ela atribuído.

De "autora improvável" (ALMEIDA, 2020) Carolina de Jesus foi descoberta e revisitada por novas gerações de leitores que, 60 anos após a primeira publicação da obra, reconhecem seu legado literário - inspirando e mobilizando mulheres com trajetórias semelhantes à sua (DOS SANTOS, 1996) - e a atualidade dos temas nela abordado, em especial a fome.

Tendo em vista a relevância de Quarto de Despejo e no ensejo do $60^{\circ}$ aniversário de sua publicação, o objetivo do artigo que segue é analisar a obra ${ }^{3}$ enfatizando o olhar na centralidade da escrita no cotidiano de Carolina de Jesus e as consequências de tal ação: instrumento de construção de uma narrativa de si, como meio de resistência (principalmente em relação à fome) e expressão da consciência política.

3 Neste artigo utilizamos a versão publicada em 2014 pela Editora Ática. 


\section{O CAMINHO METODOLÓGICO}

Antes de apresentarmos a análise da obra supracitada cabe apresentarmos algumas questões acerca do caminho metodológico adotado nesse artigo: em primeiro lugar consideramos Quarto de Despejo como uma fonte histórica, um vestígio do passado, que nos possibilita reflexões acerca da condição da mulher negra, favelada e única responsável pela educação e sustento dos filhos na década de 1950. Nesse sentido, se a chamada História das Mulheres pode ser comparada a um artefato arqueológico soterrado sob muitos séculos de desconsideração e rejeição, questões do presente (relacionadas com mudanças sociais, políticas, econômicas e acadêmicas) ${ }^{4}$ colaboram para que vozes outrora silenciadas possam ser atualmente escutadas.

Sobre a escuta das vozes do passado, De Almeida (2014, p. 347) afirma que: "[...] no caso feminino, os documentos e as fontes escritas se situam na maioria no universo doméstico, na literatura dirigida às mulheres, nas cartas, diários íntimos, diários escolares, fragmentos da memória, entre outros". Os diários íntimos, portanto, são fontes relevantes para pesquisadores que se propõem estudar a História das Mulheres (De Andrade, 2009).

Ao realizar uma reflexão sobre diários, escrita e experiências femininas, Milan (2016) nos chama a atenção para o fato de que historicamente a produção desse gênero textual está historicamente relacionada com às pessoas de poder aquisitivo e que, a partir da escrita, posicionavam-se como protagonistas de sua história.

Nesse ponto, se os diários normalmente trazem à tona as memórias das mulheres das chamadas classe médias e alta e com acesso à escolarização, Quarto de despejo, enquanto artefato, nos apresenta outras percepções: 1) rompe com o imaginário acerca dos "Anos Dourados" (1945-1964) e apresenta a outra face da ampliação e sofisticação das relações capitalistas em nosso país: o rosto da mulher que batalhava todos os dias para não deixar os filhos passarem fome. 2) Apresenta a escrita não como privilégio, mas como um prazer diante de um cotidiano difícil e como um instrumento para a elaboração de outra imagem de si, a Carolina escritora, ainda que para muitos fosse uma "autora improvável".

É relevante salientar que os textos autobiográficos, quando deixam o espaço privado para se tornarem públicos, se tornam obras passíveis de críticas para diferentes sujeitos: desde um público amplo, aos leitores especializados, tais quais os historiadores ou especialistas em crítica literária, por exemplo. Para De Sousa (2011 p. 90) "o gênero autobiográfico, devido a sua especificidade - o limite tênue entre o real e ficcional -, sempre suscitou desconfianças por parte da crítica".

\footnotetext{
4 Como um exemplo dessa preocupação/alteração citamos uma pesquisa por Regina Dalcastagné em 2012 e divulgada por Santana (2019). Ao observar o perfil dos autores das obras literárias (um total de 258 livros) publicadas entre os anos de 1990 a 2004 por três editoras consagradas no cenário nacional observou que $93 \%$ eram brancos e $72 \%$ homens. Os números expressam as dificuldades que as escritoras negras enfrentam para terem seu trabalho divulgado e reconhecido e, a pesquisa de Regina Dalcastagné demonstra que cada vez mais há pessoas preocupadas com o sexismo e o racismo presente na produção, publicação e divulgação de obras com teor literário.
} 
A ESCRITA

Eu cato papel, ferro, e nas horas vagas escrevo (DE JESUS, 2014, p.105)

Virginia Woolf (1990) na clássica conferência transformada no livro "Um teto todo seu" instigou o seu público a pensar a relação entre as mulheres e a escrita literária como algo mais profundo que simplesmente prestar um tributo àquelas que deixaram suas contribuições na história da literatura; para a autora era importante considerarmos as condições de existência que possibilitavam, ou limitavam, as mulheres a se tornarem escritoras. Woolf enfatizou sua análise na desigualdade entre homens e mulheres e nos elementos que impediam que essas últimas acessassem às universidades e o que elas representam (o acesso ao conhecimento, às memórias e desenvolvimento de ideias individuais e coletivas).

As questões colocadas por Virginia Woolf continuam tendo relevância, mas precisamos inserir nessa análise questões para além do gênero, pois as desigualdades sociais perpassam também outros elementos. Da Rosa e Da Silva (2020) nos chamam a atenção para a pertinência da noção de colonialidade para esse debate entendendo-a como um resquício violento do processo colonial do qual o Brasil passou. Entre as marcas visíveis, ainda hoje, em nossa sociedade estão o apagamento das contribuições intelectuais e literárias das escritoras negras. Assim, argumentam que "[...] antes de construírem as identidades do "negro" e do "índio", os colonizadores reproduziram as identidades sociais do "homem" e da "mulher" (DA ROSA, DA SILVA, 2020, p. 2).

Ao analisarmos o trabalho de Carolina de Jesus, não podemos ignorar o que os autores chamaram de "permanência da visão colonizadora racista e patriarcal" (DA ROSA, DA SILVA, 2020, p.2) presente em várias esferas sociais ao longo dos anos 1950 e 1960 e que, no campo acadêmico, fazia com que Carolina fosse exatamente o oposto do que se esperava daqueles que se dedicavam à escrita. Ela era uma "escritora improvável" (ALMEIDA, 2020) e o "silêncio" e o "anonimato" (DA ROSA, DA SILVA, 2020) eram o destino previsto. A análise da obra nos mostra que a escritora tinha consciência da situação, embora tenha se rebelado por meio da escrita.

Maria Carolina de Jesus (2014, p. 23) relatou em seu diário o seguinte diálogo com um desconhecido: "[...] enquanto as roupas corava eu sentei na calçada para escrever. Passou um senhor e perguntou-me: - O que escreve? - Todas as lambanças que pratica os favelados, estes projetos de gente humana". Ao analisar a fonte, é possível perceber a curiosidade do homem que observou Carolina. Para entender o espanto demonstrado no diálogo, e vermos como ele expressa o racismo e o machismo da época, recorremos à De Almeida (2014, p. 344) que descreve em seu artigo as regras de civilidade existentes entre as décadas de 1920 e 1950:

No novo cenário social, as mulheres deveriam cultivar-se para viverem em sociedade e serem agradáveis aos homens. Não poderiam concorrer com eles profissional e intelectualmente, isso ultrapassaria os limites da segurança social e representaria um risco, se lhes fosse dado liberarem-se economicamente dos maridos ou dos pais e tornarem-se iguais no intelecto. 
De Almeida (2014, p. 350) ainda afirma que “[...] estas recomendações possuíam um recorte de classe, dado que se referiam a mulheres em boa situação financeira e classe social privilegiada, e não às mulheres da população em geral". Assim, as mulheres (mesmo letradas) não podiam demonstrar uma ilustração maior do que a dos seus cônjuges, uma vez que deveriam ser dependentes deles: economicamente e intelectualmente. A escrita representava um risco para ordem social vigente, pois caberia à mulher apenas o bom direcionamento do lar. Saber ler e escrever era para poucos, principalmente quando se tratando de mulheres.

As questões acima expostas auxiliam a entender o espanto do homem expresso no diálogo anteriormente citado: em primeiro lugar as mulheres não possuíam acesso à cultura letrada e as que conseguiam eram mulheres brancas oriundas de famílias com condições financeiras para custear a educação das moças. Nos casos mais raros, algumas jovens contavam com algum auxílio, como foi o caso da escritora ${ }^{5}$.

Carolina, dessa forma, desafiava os estereótipos de gênero de sua época ao fazer do gosto pela leitura e o prazer pela escrita em elementos centrais no seu cotidiano.

Vou parar de escrever. Vou torcer as roupas que ensaboei ontem. (DE JESUS, 2018, p. 34)

[...] Eu estava escrevendo, esperando o arroz secar. Guardei o caderno e fiquei girando, procurando o João. (DE JESUS, 2018, p.109).

Escrevia nos momentos disponíveis entre os afazeres domésticos e o trabalho de catadora e lavadeira, ou ainda de noite enquanto os filhos dormiam.

Se a dedicação à escrita causava espanto por romper com o que socialmente se esperava de uma mulher, o fato de Carolina ser negra e morar na favela do Canindé também são elementos que faziam dela uma escritora improvável. Em seu diário narrou o seguinte diálogo:

“... Eu escrevia peças e apresentava aos diretores de circos. Eles respondia-me:

- É pena você ser preta. (DE JESUS, 2018, p.64).

Em outro momento descreveu a seguinte cena: “[...] sentei ao sol para escrever. A filha da Silvia, uma menina de seis anos, passava e dizia: - Está escrevendo, negra fidida! A mãe ouvia e não repreendia. São as mães que instigam”. (DE JESUS, 2014, p. 26).

Os trechos acima expressam não apenas o preconceito racial existente no Brasil da época, mas também a consciência de Carolina de Jesus em relação a existência do racismo. Tais questões não a impediram de escrever, ao contrário, eram transformados numa espécie de motor que a impulsionava. Aprendemos com Foucault (1992) que a escrita pode ser compreendida como uma forma de subjetivação e que possui uma historicidade; desta

5 De acordo com Da Costa (2007, p. 18), Carolina “[...] frequentou o Colégio Allan Kardec, de Sacramento, instituição financiada por Maria Leite Monteiro de Barros, para quem a mãe de Carolina lavava roupas e que se dispôs a contribuir para a educação da menina”, entretanto, Carolina estudou por apenas dois anos. 
feita, ainda que nosso objeto de estudo seja distinto daquele do filósofo (que estudou o que denominou de escrita de si no período helenístico) acreditamos que parte das propostas utilizadas por Foucault podem ser aproveitadas para entendermos a escrita de Carolina de Jesus, em especial: a ideia da escrita de si como uma forma de constituição do sujeito e a escrita como instrumento de meditação, autocontrole e reinvenção de si. No caso de Carolina de Jesus vale ressaltar a escrita como um instrumento para a criação de uma outra imagem: primeiro dela em relação a si mesmo, segundo dos demais em relação a ela.

Priore e Bassanezi (2004, p. 487) afirmam que "normalmente, as mulheres negras são apresentadas, na documentação disponível, como figuras extremamente rudes, bárbaras e promíscuas, destituídas, portanto, de qualquer direito de cidadania”.

Carolina, longe de aceitar para si tais representações repletas dos preconceitos de raça e gênero de sua época, ao inserir a escrita em seu cotidiano como um elemento de prazer, resistência e parte fundamental de quem era e gostaria de ser, criou para si outra imagem: a escritora apaixonada pela leitura: “[...] li um pouco. Não sei dormir sem ler. Gosto de manusear um livro. O livro é a melhor invenção do homem" (DE JESUS, 2014, p.24). Desta feita, a escrita e a leitura era uma forma de prazer, talvez um dos poucos em um cotidiano marcado pela ausência do riso.

Ao analisar o processo de subjetivação de Carolina, Da Rosa e Da Silva (2020, p.4) fazem a seguinte observação:

\begin{abstract}
É bem verdade que Carolina Maria de Jesus se transformou [...] quando aprendeu a ler o mundo e a dizer a sua palavra - o que fez por meio da escrita, quando passou a registrar seu cotidiano de forma crítica e profundamente reflexiva em seus diários. Carolina se transformou por questionar as péssimas condições de vida às quais ela e os seus vizinhos e vizinhas "favelados/as" eram submetidos por uma estrutura social injusta; por questionar as violências de gênero e raça.
\end{abstract}

As caricaturas e preconceitos construídos pelo racismo estrutural, pela misoginia e diferenças de classe presente no Brasil do período foram compreendidos por Carolina e, em alguns casos, respondido de acordo com suas possibilidades. Pode-se observar no seguinte trecho: “[...] passou um senhor, parou e nos olhou. E disse perceptível: - Será que este povo é deste mundo? Eu achei graça e respondi. - Nós somos feios e mal vestidos, mas somos deste mundo". (DE JESUS, 2014, p. 145).

\title{
FOME E POLÍTICA
}

Observamos que Carolina não se contentou em relatar as dificuldades cotidianas, mas também em refletir sobre as causas. Chegou à conclusão de que havia uma articulação entre racismo, fome e política. Ao analisar a sua vida, descreveu-a utilizando as seguintes palavras:

A vida é igual um livro. Só depois de ter lido é que sabemos o que encerra. E nós 
quando estamos no fim da vida é que sabemos como nossa vida decorreu. A minha, até aqui, tem sido preta. Preta é a minha pele. Preto é o lugar onde eu moro. (DE JESUS, 2014, p. 167)

Mais do que um tom disposto numa paleta de cores "preto", para Carolina, expressava o lugar que ocupava (e a consciência de ocupar esse lugar) e as suas condições materiais de existência. Articulada com a cor preta, as páginas do diário são marcadas pela frase "estou com fome". Dos Santos e Scherer (2012, p. 93) argumentam que "as causas da fome estão atreladas à persistência de restrição de acesso aos alimentos, motivadas principalmente pela questão econômica"; entretanto, ainda que a definição seja tecnicamente correta, há um outro elemento, apresentado por Carolina, e que não podemos perder de vista: “é preciso conhecer a fome para descrevê-la". (DE JESUS, 2018, p. 29). Em outras palavras, Carolina expressava que a fome não era uma abstração, mas parte de uma experiência marcada pela batalha diária para alimentar os filhos: "e assim no dia 13 de maio de 1958 eu lutava contra a escravatura atual - a fome!” (JESUS,2018, p. 32). Se a Abolição da Escravatura igualava-a como uma cidadã livre, em sua perspectiva, a fome tornava-a desigual em relação aos demais.

De acordo com Dos Santos e Scherer (2012) a fome é uma questão social que nos acompanha desde o período colonial; entretanto, foi somente na era da ditadura de Vargas que políticas voltadas para a alimentação foram instituídas. Aproximadamente seis décadas depois, em 2003, foi lançado pelo ex-presidente Luiz Inácio Lula da Silva o programa Fome Zero no Brasil. Antes existiam outros programas sociais, embora este tenha recebido maior notoriedade devido ao seu impacto social. Nesse contexto, o prato vazio tornou-se emblemático, ajudando a conscientizar sobre a condição de muitos brasileiros.

Para Dos Santos e Scherer (2012, p.93) "os desdobramentos reais da política brasileira de combate à pobreza ainda não conseguiram atingir, as raízes da miséria, cabendo ainda, a esse montante da população, um estado de absoluta carência", condição que se refere não apenas a privação de alimentos, mas a falta de moradia, saúde e trabalho.

Décadas antes, Carolina de Jesus enfatizava que um país que quisesse ser considerado desenvolvido não poderia permitir que parte de sua população passasse fome:

Para mim o mundo em vez de evoluir está retornando a primitividade. Quem não conhece a fome há de dizer: "Quem escreve isto é louco". Mas quem passa fome há de dizer:

- Muito bem, Carolina. Os gêneros alimentícios deve ser ao alcance de todos. (2018 p. 38)

Em outros momentos questiona: "será que os pobres de outro País sofrem igual aos pobres do Brasil?” (JESUS, 2018, p.33).

O Plano de Metas do governo Juscelino Kubitschek propunha o desenvolvimento do setor de energia, transporte, alimentação, industrialização, educação e a construção de Brasília. Conforme Kapp, Stremel e Chaves (2019, p 23) "entre 1955 e 1961 o Produto Interno 
Bruto nacional cresceu 7,9\% ao ano e a importação de bens de capital (nesse mesmo período) praticamente dobrou", mas o rápido desenvolvimento econômico da era JK não atingiu a todos os brasileiros. Diferentemente do progresso aclamado no Brasil da década de 1950, com o presidente da Bossa Nova, Carolina de Jesus escrevia sobre outra realidade: a fome pela qual muitos brasileiros da época enfrentavam. Essa mesma fome que, além do corpo, marcava também o emocional de muitos brasileiros. Carolina cita em seu diário o caso de uma mulher que cometeu suicídio. $\mathrm{Na}$ base da tragédia estava as dificuldades em manter uma vida digna. Ao refletir sobre o caso argumentou: “[...] é uma vergonha para uma nação. Uma pessoa matar-se porque passa fome” (DE JESUS, 2018, p.63).

A fome, conforme observou, foi utilizada como uma espécie de "pauta política" para muitos políticos que objetivavam conquistar votos:

...Quando um politico diz nos seus discursos que está ao lado do povo, que visa incluir-se na politica para melhorar as nossas condições de vida pedindo nosso voto prometendo congelar os preços, já está ciente que abordando este grave problema ele vence nas urnas (DE JESUS, 2018, p.38).

A abordagem constante do tema, mas a ausência de resolução, fazia com que a escritora tivesse a consciência de que "quem governa o nosso país é quem tem dinheiro, quem não sabe o que é fome, a dor, e a aflição do pobre" (DE JESUS, 2018, p.39). Não sabe, no sentido de não ter passado por tal experiência, embora tivesse consciência do problema, inclusive aproveitando-se da questão para manter-se na política.

$\mathrm{Na}$ data de 16 de maio de 1958 a autora fez o seguinte registro: "eu quando estou com fome quero matar o Janio, quero enforcar o Adhemar e queimar o Juscelino. As dificuldades corta o afeto do povo pelos políticos". (DE JESUS, 2018, p.33). O sentimento de revolta proporcionado pela fome gerava não apenas desafeto com as figuras que comandavam o país naquele contexto, mas também uma desilusão com a própria democracia: [...] A democracia está perdendo os seus adeptos. No nosso paiz tudo está enfraquecendo. O dinheiro é fraco. A democracia é fraca e os politicos fraquissimos. E tudo o que está fraco, morre um dia. (DE JESUS, 2018, p.39.).

A consciência sobre a dimensão política da fome (e como a presença desta enfraquece as bases de uma sociedade democrática) é acompanhada da certeza de que as pessoas ocupam espaços distintos na cidade. Sobre o assunto escreveu: "Eu classifico São Paulo assim: O Palácio, é a sala de visita. A Prefeitura é a sala de jantar e a cidade é o jardim. E a favela é o quintal onde jogam os lixos". (DE JESUS, 2014, p. 32).

Ainda que não delimitada com muros a cidade era dividida sendo vedada a livre circulação, exceto para os políticos que, em épocas de eleições, andavam pelas favelas comportando-se como se sempre caminhassem por aqueles lugares. Entretanto, se o político poderia ir no "quarto de despejo" quando bem entendesse, o favelado não poderia frequentar a "sala de visita", a "sala de jantar" e o "jardim".

Ao narrar a ida a um determinado edifício para receber alguns papeis descreveu vários constrangimentos que expressam as interdições em relação a ocupação e circulação dos sujeitos no espaço da cidade: 
No sexto andar o senhor que penetrou no elevador olhou-me com repugnância. Já estou familiarisada com estes olhares. Não entristeço.

[...] Perguntei-lhe se era medico ou deputado. Disse-me que era senador.

O homem estava bem vestido. Eu estava descalça. Não estava em condições em andar no elevador.

Pedi ao jornaleiro para ajudar-me a por o saco nas costas, que o dia que eu estivesse limpa eu lhe daria um abraço. Ele sorriu e disse-me:

- Então já sei que vou morrer sem receber o teu abraço, porque você nunca está limpa. (DE JESUS, 2018, p.111)

O trecho acima relata um dos dias em que Carolina teve maior retorno financeiro com seu trabalho enquanto catadora, mas também um dos dias em que mais foi violentada: pelos olhares, com palavras, pelo cansaço, etc. Ainda que tentasse argumentar, para si mesma, que estava habituada com tal situação, o registro em seu diário nos deixa pistas de uma alma que sofria. Tal percepção acentua-se com a frase que termina de narrar aquele dia: “... Fui deitar-me. As pulgas não me deixou em paz. Eu já estou cançada desta vida que levo.” (DE JESUS, 2018, p.111).

\section{CONSIDERAÇÕES FINAIS}

Aproveitamos o aniversário de lançamento da primeira edição de Quarto de despejo para refletirmos sobre escrita, fome e política a partir da ótica de Carolina de Jesus. Ao relatar seu cotidiano (marcado pelo racismo, pelo machismo e pela extrema-miséria) a escritora não narrou apenas a sua história, mas a de inúmeros brasileiros ignorados pelas narrativas ufanistas que ressaltavam apenas os aspectos positivos dos chamados Anos Dourados.

Ao dedicar-se à escrita enquanto um elemento de construção de outra imagem de si, como ferramenta de prazer em contexto marcado pela fome e como mecanismo de reflexão sobre essa realidade, Quarto de despejo rompe com uma característica recorrente dos chamados diários (suporte das memórias das mulheres de classe média e alta e com acesso à educação formal) para tornar-se uma fonte histórica que retrata o cotidiano de mulheres dos anos 1950-1960 e que lutavam, todos os dias, contra os preconceitos de classe, gênero e raça.

Nesse sentido, longe de ser um privilégio a escrita era um instrumento para a construção de uma outra Carolina, a escritora, ainda que “improvável” para muitas devido a mentalidade colonizadora racista e machista que imperava no Brasil da época: não só no campo literário, mas em várias esferas do corpo social e que foi responsável pelo silenciamento de inúmeras vozes tão ricas e interessantes tais qual a de Carolina.

A fome, grande presença na escrita de Carolina, enfraquecia não apenas o seu corpo, 
sua autoimagem (enquanto mulher/mãe) e sonhos; conforme observou (e mais tarde foi possível observarmos) enfraquece as bases de uma sociedade democrática. Enquanto 'favelada' sentia o descaso, dos políticos e da sociedade, para com a sua realidade e tinha consciência de que a fome era um projeto político.

Ainda que renegada por seus vizinhos de favela sentia-se pertencente àquele grupo. Sabia que as desilusões e amarguras existentes em sua trajetória não eram apenas suas, mas também de todos aqueles que viviam no "quarto de despejo". Sofria e tinha consciência de que parte desse sofrimento era efeito das ações políticas e sociais tomadas na "sala de visita", "jantar" e no "jardim". 


\section{REFERÊNCIAS}

ALMEIDA, Liz Costa. O legado histórico de Carolina Maria de Jesus. ADFRJ. 2020. Disponível em: https://www.adufrj.org.br/index.php/pt-br/noticias/arquivo/21-destaques/3432-o-legado-historico-decarolina-maria-de-jesus

DA COSTA, Renata Jesus. Subjetividades femininas: mulheres negras sob o olhar de Carolina Maria de Jesus, Maria Conceição Evaristo e Paulina Chiziane. 2007, 152 f. Dissertação (Mestrado em História Social) - Pontifícia Universidade Católica, São Paulo, 2007.

DA ROSA, Carolina Schenatto; DA SILVA, Gilberto Ferreira. Carolina Maria de Jesus e o pensamento liminar na literatura brasileira. Revista Estudos Feministas, Florianópolis.

DE ANDRADE, Letícia Pereira. Quarto de despejo: a literatura memorialística feminina. Travessia, UNIOESTE, v. 3, n. 1, s/p, 2009.

DE ALMEIDA, Jane Soares. Mulheres no cotidiano: educação e regras de civilidade (1920/1950). Dimensões, UFES v.33, pg. 336-359, 2014.

DE SOUSA, Gernama Henriques Pereira. Memória, autobiografia e diário íntimo: Carolina Maria de Jesus: escrita íntima e narrativa da vida. In: Hermenegildo Bastos; Adriana de F. B. Araújo (Org.). Teoria e prática da crítica literária dialética. Brasília, DF: Editora Universidade de Brasília, 2011, p. 86108.

DOS SANTOS, Andreia Mendes; SCHERER, Patricia Teresinha. Política alimentar brasileira: fome e obesidade, uma história de carências. Textos e Contextos v. 11, n 1, p 92-105, jan/jul, 2012

DOS SANTOS, Andrea Paula Ponto de vida: cidadania de mulheres faveladas. São Paulo: Editora Loyola, 1996. $151 \mathrm{p}$.

DE JESUS, Carolina Maria. Quarto de despejo diário de uma favelada. 10. ed. São Paulo: Editora Ática, p. 199, 2014.

FOUCAULT, Michel. A escrita de si. In: O que é um autor? Lisboa: Passagens. 1992. pp. 129-160.

PRIORE, Mary Del; BASSANEZI, Carla. História das mulheres no Brasil. 7. ed. São Paulo: Editora Contexto, p. 430- 487, 2004.

KAPP, Amanda Cieslak; STREMEL, Marion Regina; CHAVES, Niltonci Batista. Licenciatura em História: História do Brasil IV. NUTEAD/UEPG. 2019.

MILAN, Letícia Portela. Escrita de si e diários: construções do gênero diante de paradigmas socioculturais. Revista Brasileira de História e Ciências Sociais. Vol 8, n. 15, 2016. P. 154-172. 
SANTANA, Bianca. Autoras e autores negros na literatura brasileira. Ponto - Literatura. Disponível em: http://revistaponto.com.br/literatura/autoras-e-autores-negros-na-literatura-brasileira-2/. Acesso em: nov. 2019

WOOLF, Virginia. Um teto todo seu. Tradução Vera Ribeiro. Edição integral. São Paulo. Círculo do Livro. p. 141, 1990. 